\section{PROSPECTIVE STUDY ONTHE FUNCTIONAL OUTCOME OF INTERTROCHANTERIC FRACTURES TREATED WITH PROXIMAL FEMORAL NAIL: IS ITS USE STILL RELEVANT?}

\section{Original Article Orthopaedics}

Bhaskara.K ${ }^{1}$, Taranath $\mathbf{N}^{2}$, Sachin Ranvir ${ }^{3}$, Shivkumar Patil ${ }^{4}$

1 - Dr. Bhaskara KMS (Ortho), Head of the department, Department of Orthopedics, Raichur Institute of Medical Sciences, Raichur, Karnataka. 584101

2 - Dr. Taranath NMS, DNB (Ortho) Senior Resident, Department of Orthopedics, Raichur Institute of Medical Sciences, Raichur, Karnataka. 584101

s - Dr. Sachin Ranvir DNB, D' Ortho Clinical associate, Department of orthopaedics, Reliance hospital, Kopar Khairane, Navi Mumbai.400710

4 - Dr. Shivkumar Patil D' Ortho Senior Resident, Department of Orthopedics, Raichur Institute of Medical Sciences, Raichur, Karnataka. 584101

\author{
Corresponding Author: \\ Dr Taranath N \\ Senior Resident, Dept of Orthopedics, \\ Raichur institute of medical sciences, \\ Raichur, Karnataka. 584101 \\ E mail: taranathnandini2311@gmail.com \\ Mobile: 9743624393
}

Article submitted on: 14 May 2019 Article Accepted on: 19 May 2019

\begin{abstract}
Purpose: To evaluate clinical and functional outcomes of use of proximal femoral nail (PFNs), a popular mode of fixation in the treatment of intertrochanteric fractures of the proximal femur.

Methods : Over a period of 10 months starting from Jan 2017 to Nov. 2017, 20 patients, diagnosed with proximal femoral fractures were included in this prospective study after having taken ethical clearance from the institution. All fractures were classified using Boyd Griffin classification. All cases were treated with PFN by a single surgeon. Functional score was assessed using Harris hip score before fracture and at follow up. Regular follow up was carried out at 4,6,8,12 weeks and then at 6 and 12 months.

Results : Twenty patients with intertrochanteric fractures, 9 males and 11 females with a mean age of 61.7 years took part in the study. Based on the Boyd and Griffin classification $35 \%, 40 \%$ and $25 \%$ respectively were classified as types 2, 3 and 4 fractures. There were no intraoperative complications. Six cases required open reduction as attempts at closed reduction failed to achieve the desired fracture reduction. Tolerated weight bearing was allowed at second to tenth postoperative day. The mean follow up period was 12.5 months (8 - 17 months). None of the cases had fixation failure, loss of reduction, collapse of the neck, nonunion or deep infection. Two of
\end{abstract}

the cases had superficial infection which were treated successfully with a course of antibiotics and dressings.

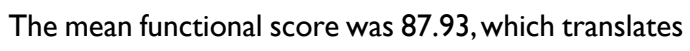
to a Good outcome.

Conclusion : Our study shows that PFN when used for intertrochanteric fractures provides good to excellent functional results thus justifying its continued popularity even after 20 years after its introduction and despite the emergence of many variations in its design.

Keywords: Proximal femoral nail, PFN, outcomes, surgical treatment, Intertrochanteric fractures 


\section{Introduction}

There has been a dramatic increase in the number of proximal femoral fractures in the recent decades. ${ }^{1}$ Most of these occur in elderly patients and about $32 \%$ of those who sustain the fracture die within an year of the injury. ${ }^{2}$ Occurrence of a proximal femur fracture reduces life expectancy by 1.8 years and $1 / 5^{\text {th }}$ of the remaining life is spent with dependency on long term care services. ${ }^{3}$ Only $50 \%$ of those who survive beyond 6 months after the injury achieve pre fracture functional state. ${ }^{4}$ It has been proven that mortality in this group of patients can be reduced by early surgical intervention, early mobilisation and load bearing ${ }^{5,6}$.

Fifty percent of hip fractures in elderly patients are intertrochanteric fractures while more than $50 \%$ of these are of the unstable variety. ${ }^{8,9}$ Hip fractures are bimodal in age distribution; $>95 \%$ occur in patients older than 50 years while $<5 \%$ occur in patients younger than 50 and are concentrated between 20 and 40 years. In the elderly and in patients with low bone stock, unstable pattern of fractures are common. ${ }^{10}$ Fractures in patients between 40- 50 yrs old occur in those who have multiple illnesses or are chronic alcoholics. ${ }^{11,12}$ As per Watson and Jones, intertrochanteric fractures heal but are prone to coxa vara and shortening thus limiting mobility and prolonging recumbency in the primary population it affects, the elderly. Thus, the aim in treating these fractures should be to encourage union without deformity and at the same time allow early mobilisation with minimal medical complications and technical errors $^{13,14}$.

Achieving uneventful fracture union and early mobility depends on the biomechanical properties of the fixation device. ${ }^{7}$
Fixation of Intertrochanteric fractures began in the 1950s to preclude complications associated with prolonged immobilisation and bed rest ${ }^{15,16}$.

Extramedullary devices like DHS have proved to be good for stable fractures patterns while frequent complications have been seen when used for unstable ones. ${ }^{17}$ In comparison, PFN is an intramedullary device, thus having a shorter lever arm causing lower bending moment and lower rates of mechanical failure when used in unstable fracture patterns. It also has the advantage of being a load sharing device, having a smaller incision, lesser blood loss, lower wound complications and lower operating time. However, it has disadvantages like jamming of sliding mechanisms, screw cutout, tip and distal lock stress riser, $\mathrm{Z}$ and reverse $Z$ effect. ${ }^{18,19,20}$ Other complications like early and late implant tip diaphyseal fractures have lead to unjustification of use of short PFNs by some studies. ${ }^{21,27}$ However, newer PFN designs have several modifications to overcome the shortcomings ${ }^{28}$.

Proximal femoral nail belongs to class 3 of nails described by Russell. They are reconstruction class of nails developed by Russell and Taylor. They have a proximal lateral bend (Mediolateral angle) of 4 to 6 degrees. They have a proximal nail diameter measuring 13 to $15 \mathrm{~mm}$ and are trochanteric portal designs. ${ }^{29}$ A CCD of 130/ 135 degrees. It has advantages of being a closed technique. Has a $11 \mathrm{~mm}$ neck screw which acts as a compression screw at the fracture while a $6.5 \mathrm{~mm}$ neck screw acts as an anti rotation screw. They act by the principle of dynamic compression. However, they have been found to fail by the $\mathrm{Z}$ effect phenomenon in fractures with medial comminution and with varus positioning of the implant. ${ }^{30,31,32}$ The interTAN type of fourth generation nails are rarely available and less popular in India and we have had no experience with the use of this class of nails.

\section{Materials and methods}

The study was carried out at Raichur institute of medical sciences (RIMS) and thus was a single site study. 20 cases with Intertrochanteric fractures between January to November 2017 were included in this prospective study. Ethical clearance was obtained from the institute's ethical committee. Radiographic confirmation of diagnosis was obtained. Boyd and Griffin classification was used to classify the fractures. Types 2, 3 and 4 were included in the study. Patients unfit for surgical intervention, those that were unwilling for surgery, patients with terminal illness and malignancies with a short life expectancy, patients with cognitive disturbances, those with polytrauma, those who were non ambulant before the injury were excluded from the study. All routine preoperative blood investigations, preliminary cardiorespiratory examination was carried out and fitness for surgery was obtained from the medicine department in the institute.

All cases were carried out under subarachnoid block. The operating surgeon was the same for all the 20 cases. The patient was supine on a traction table with the injured limb in longitudinal traction and the contralateral leg placed in a well leg holder. Reduction was achieved with longitudinal traction and internal rotation of varying degrees in different patients. The reduction was checked in AP and lateral views 
under fluoroscopy. The fracture was considered to be reduced when the main fracture fragments were well aligned in both the views. Baumgartner's criteria was used to assess quality of reduction intraoperatively. Long nails were preferred for types 3 and 4 while short nails were used for type 2. In $80 \%$ of cases 135 degree nails were used while 130 deg was used in the rest of the patients based on the preoperative templating. In $30 \%$ of cases open reduction had to be carried out to obtain satisfactory reduction of the fracture. A tip apex distance of $<24$ was aimed for in all cases. Prophylactic intravenous antibiotics were used 30 minutes prior to the incision in all cases. Postoperatively all patients were put on empirical antibiotics for 5 days. Knee and ankle movements were started from the first postoperative day. All patients were allowed tolerated wt bearing from the second to tenth postoperative days. Radiographic assessment was done on postoperative day 1, weeks 4 and 6 and then at 3rd and 6th month.

Table 1: Quality of reduction was assessed using modified Baumgaertner criteria: ${ }^{33}$

\begin{tabular}{|l|l|}
\hline \multicolumn{2}{|l|}{ Modified Baumgaertner Criteria } \\
\hline Alignment & $\begin{array}{l}\bullet \text { AP: normal CCD } \\
\text { angle or slight } \\
\text { valgus } \\
\bullet \text { Lateral: }<20 \\
\text { degree angulation }\end{array}$ \\
\hline $\begin{array}{l}\text { Displacement } \\
\text { Of Fragments }\end{array}$ & $\bullet>80 \%$ overlap \\
\hline - Assessment: \\
- Both criteria met $\longrightarrow$ Good \\
- One criteria met $\longrightarrow$ Satisfactory \\
- None of the criteria met $\longrightarrow$ \\
Poor
\end{tabular}

\section{Results}

Twenty patients with intertrochanteric fractures, 9 males and 11 females with a mean age of 61.7 , ranging between 35 to 80 years, took part in the study. Based on the Boyd and Griffin classification 7 (35\%) belonged to type $2,8(40 \%)$ to type 3 and 5 (25\%) were of type 4 fractures types. The average duration from admission to the day of surgery was 6.25 days. There were no intraoperative complications. Six cases $(30 \%)$ required open reduction as attempts at closed reduction failed to achieve the desired fracture reduction. Intraoperatively, in one case only a single head screw, the compression screw alone, could be passed. This may be due to the smaller built of the patient. This patient's last follow up was at 8th month and her funcional score was Fair and the fracture was uniting as expected without any complications. The mean surgical time was 32 mins with a range of $20-65$ mins. Tolerated weight bearing was allowed at second to tenth postoperative day. The mean follow up period was 12.5 months ( 8 - 17 months). Postoperatively, limb shortening was noticed in two patients, at 12th and 18th month follow up, attributed to late varus collapse of the fracture. Both the patients had highly comminuted fracture patterns, had undergone open reduction and fixation, despite which, their Baumengatern quality of reduction on post operative radiographs were classified as poor. Two of the cases had superficial infection, within the 1 st week of the surgery, which were treated successfully with a course of antibiotics and dressings.

The mean functional score was 87.93, ranging from 66.8 to 100 . Eleven cases $(55 \%)$ had excellent results, 4 (20\%) good, 4 (20\%) fair and $1(5 \%)$ were poor results. There were no re-operations or any mortality during the study period.

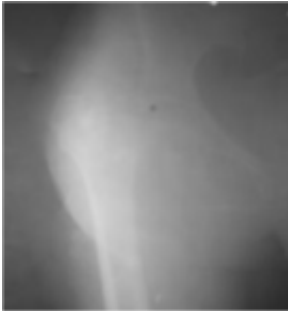

Fig-1: a) Boyd and Griffin classification type 2 intertrochanteric fracture

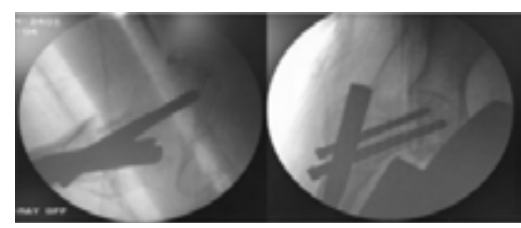

b) \& c) Intraoperative assessment of quality of fracture reduction appears to be good as per Baumgartner's criteria.

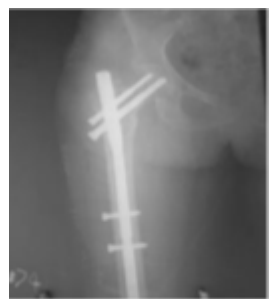

d) Post operative radiograph at 3rd month follow up

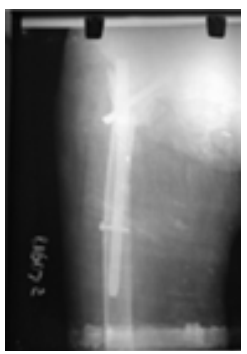

Fig-2: A case where only a single compression cephalic screw is passed due to a short neck. Follow up radiograph at 8th month.

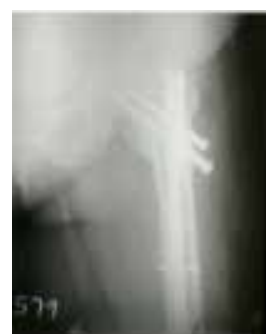

Fig 3: A type 3 intertrochanteric fracture treated with PFN radiograph showing satisfactory fracture healing at 1 year and 4 months follow up. 

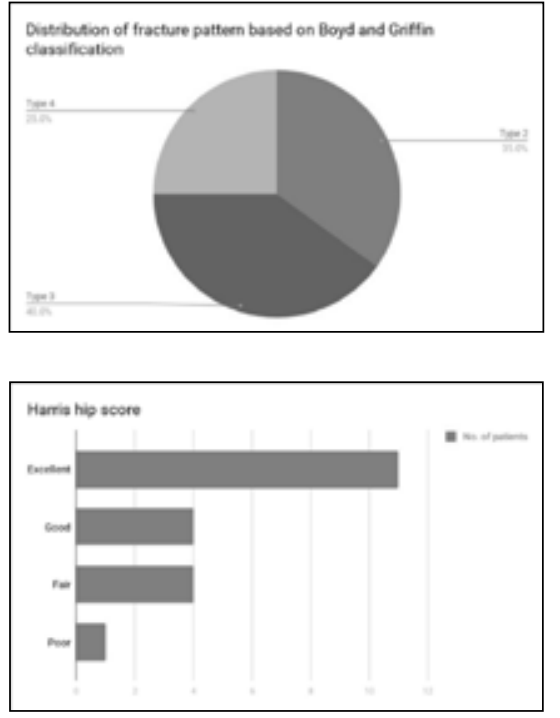

\section{Discussion}

This study is a prospective study on functional outcomes of unstable intertrochanteric fractures (Boyd and Griffin types 2 to 4 ) treated with open or closed reduction with a popular mode of fixation, the proximal femoral nail (PFN). Type 1 fractures, being stable fractures, were treated with Dynamic hip screw, a Screw and plate system.

PFN belongs to a reconstruction class of nail with two proximal dynamic compression screws. They are trochanteric portal designs and have lateral bend of about 4 to 6 degrees proximal to the lesser trochanteric region while having a proximal nail diameter of 13 to 15 mm. ${ }^{34}$ Cephalomedullary implants are considered to be biomechanically more stable than extramedullary implants. ${ }^{35}$ Intramedullary devices provide axial telescoping and rotational stability and are well tolerated by elderly being minimally invasive. ${ }^{36}$ In addition PFNs give anti rotation stability owing to the anti rotation head screw and accommodate the medullary canal well because of their unique design of a larger proximal diameter and a smaller distal shaft diameter. ${ }^{37}$ The mean age of the cohort in our study was 62 yrs in comparison to $79.9,74$ and 84 yrs accordingly in studies by Babst et al, Klinger et al and Alyassari et al. ${ }^{38,39,40}$

The mean duration of surgery, skin to skin, as per Simmermcher et al, Pajarinan et al and Wang et al were $68.7,55$ and 90 mins were as that in our study was 32 mins ranging from 65 to 20 mins. This difference may be credited to all the cases in this study having been operated by a single surgeon, the most experienced orthopedician of the institute..$^{41,42,43}$

The average blood loss per operatively also was less, being about $100 \mathrm{ml}$ (assessed by soaked mops) highlighting minimally invasive nature of the technique involved in the use of this implant.

There were no intraoperative technical or mechanical problems like difficulty in distal locking or lateral wall fractures as were described by Fogagnolo et al (23.4\%). However, in 1 case we had difficulty in proximal cephalic screw passage leading to this cases being fixed with only one cephalic screw. There were no cases of guide wire breakage, iatrogenic fractures of the shaft of femur, no cases of varus or valgus reduction as per Baumgaertner criteria ${ }^{44}$.

Post operative complications like heterotopic ossification was noted in 1 of 83 cases of PFN by Pajarinan et $\mathrm{a}^{45}$, Werner et al documented $7.1 \%$ of cases having $\mathrm{Z}$ effect and $8.6 \%$ cases having screw cut out. ${ }^{46}$ We had 2 cases of superficial infection of the surgical site which were treated successfully with antibiotic therapy and two cases of varus collapse of the fracture noted at 6 weeks from the time of the surgery and 2 cases of limb shortening of $>2$ cms. There were no cases of deep infection, Deep vein thrombosis,
$\mathrm{Z}$ effect, heterotopic ossification, delayed or nonunion.

Excellent results were found in $32 \%$, good in $52 \%$ and fair in $16 \%$ of cases treated with PFN in a study by Kiran kumar et al using Harris hip score while our study had $55 \%$ of excellent, $20 \%$ of good, $20 \%$ fair and $5 \%$ poor results. ${ }^{47}$

\section{Conclusion}

Our study shows that PFN when used for intertrochanteric fractures provides good to excellent functional results thus justifying its continued popularity even after 20 years after its introduction and despite the emergence of many variations in its design.

\section{References}

1. Senohradski K, Markovic-Denic L, Lesic A, Bumbasirevic V, Bumbasirevic M. Trends in the incidence of hip fractures. Osteoporos Int. 2013;24:1759-63. doi:10.1007/s 00198-012-2244-y.

2. Ngobeni RS. Mortality in elderly patients with intertrochanteric fractures: three years' experience. SA Orthop J. 2010;9:55-60.

3. Braithwaite RS, Col NF, Wong JB. Estimating hip fracture morbidity, mortality and costs. J Am Geriatr Soc. 2003;51: 364-70.

4. Magaziner J, Fredman L, Hawkes W, Hebel JR, Zimmerman S, Orwig DL, Wehren L. Changes in functional status attributable to hip fracture: a comparison of hip fracture patients to community dwelling aged. Am J Epidemiol. 2003;157:1023-31. doi:10.1093/ aje/kwg081.

5. Hallberg I, Bachrach-Lindstro $\mathrm{m}$ M, Hammerby S, Toss G, Ek AC. Health-related quality of life after vertebral or hip fracture: a sevenyear follow-up study. BMC Mus- 
culoskelet Disord. 2009;10:135. doi:10.1186/1471-2474-10-135.

6. Zlowodzki M, Tornetta P 3rd, Haidukewych G, Hanson BP, Petrisor B, Swiontkowski MF, Schemitsch EH, Giannoudis PV, Bhandari M. Femoral neck fractures: evidence versus beliefs about predictors of outcome. Orthopedics. 2009;32(4). pii: orthosupersite. $\quad \mathrm{com} /$ view.asp?rID = 38062.

7. Delee JC, Clanton To, Rockwood CA. Closed treatment of subtrochanteric fractures of femur in modified cast-brace. J Bone and Joint Surgery Am 1981; 63: 773779

8. Robert BW, James Heckman D, Charles Court Brown M. Rockwood and Green's Fractures in Adults, 2(6), 18271844 .

9. David Lavelle G. Fractures and dislocations of the hip chapter-52 in Campbell's Operative Orthopaedics, eleventh edition. Vol-3, 3237-3308

10. Koval KJ, Aharonoff GB, Rokito AS, Lyon T, Zuckerman JD. Patients with femoral neck and intertrochanteric fractures: Are they the same? Clin Orthop.1996; 330:166-172.

11. Gullberg B, Johnell O, Kanis JA. World-wide projections for hip fracture. Osteoporos Int 1997;7(5):407-413.

12. Robinson CM, Court-Brown CM, McQueen MM, Christie J. Hip Fractures in Adults Younger than 50 Years of Age .Clin Orthop Relat Res. 1995 Mar;(312):23846.

13. Al-Yassari G, Langstaff RJ, Jones JW, Al-Lami M. The AO/ASIF. proximal femoral nail (PFN) for the treatment of unstable trochanteric femoral fracture. Injury
2002; 33 -395-399.

14. Sudhir S Babhulkar, Management of trochanteric fracture; Indian journal of orthopaedics, October 2006, Volume 40: number 4: p. 210-218.

15. Schumpelick W, Jantzen PM: A new principle in the operative treatment of trochanteric fracture of the hip. J Bone Joint Surg 1988, 70-A:1297-303.

16. Pugh WL: A self adjusting nail plate for fractures about the hip joint. J Bone Joint Surg 1955, 37A:1085-93.

17. Davis TR, Sher JL, Horsman A, Simpson M, Porter BB, Checketts RG: Intertrochanteric femoral fractures: mechanical failures after internal fixation. J Bone Joint Surg Br 1990, 72B:26-31.

18. Saudan M, Lübbeke A, Sadowski $\mathrm{C}$, et al: Pertrochanteric fractures: is there an advantage to an intramedullary nail? A randomized, prospective study of 206 patients comparing the dynamic hip screw and proximal femoral nail. J Orthop Trauma 2002; 16: $386-393$.

19. Magit DP, Medvecky M, Baumgaertner MR, Intramedullary Nailing for the management of Intertrochanteric and Subtrochanteric Geriatric Fractures. Tech orthop.2004;19:153-62.

20. Werner-Tutschku W, Lajtai G, Schmiedhuber G, et al. 2002. [Intra- and perioperative complications in the stabilization of perand subtrochanteric femoral fractures by means of PFN]. Unfallchirurg 105:881-885.

21. Adams CI, Robinson CM, CourtBrown CM, McQueen MM (2001) Prospective randomized controlled trial of an intramedullary nail versus dynamic screw and plate for intertrochanteric fractures of the femur. J Orthop Trauma 15:394-400

22. Bridle SH, Patel AD, Bircher M, Calvert PT (1991) Fixation of intertrochanteric fractures of the femur. A randomized prospective comparison of the gamma nail and the dynamic hip screw. J Bone Joint Surg Br 73:330-334

23. Butt MS, Krikler SJ, Nafie S, Ali MS (1995) Comparison of dynamic hip screw and gamma nail: a prospective, randomized, controlled trial. Injury 26:615-618

24. O'Brien PJ, Meek RN, Blachut PA, Broekhuyse HM, Sabhar- wal S (1995) Fixation of intertrochanteric hip fractures: gamma nail versus dynamic hip screw. A randomized, prospective study. Can J Surg 38:516-520

25. Osnes EK, Lofthus CM, Falch JA, Meyer HE, Stensvold I, Kristiansen IS, Nordsletten L (2001) More postoperative femoral fractures with the gamma nail than sliding screw plate in the treatment of trochanteric fractures. Acta Orthop Scand 72:252-256

26. Parker MJ, Pryor GA (1996) Gamma versus DHS nailing for extracapsular femoral fractures. Meta-analysis of ten randomized trials. Int Orthop 20:163-168

27. Radford PJ, Needoff M, Webb JK (1993) A prospective randomized comparison of the dynamic hip screw and the gamma locking nail. J Bone Joint Surg Br 75:789 793

28. Simmermacher RKJ, Bosch AM, Van der Werken C (1999) The $\mathrm{AO} / \mathrm{ASIF}$-proximal femoral nail (PFN): a new device for the treatment of unstable proximal femoral fractures. Injury 30: 327-332

29. Rockwood CA. Rockwood and Green's Fractures in adults 7th 
edition. Philadelphia, PA: Lippincott Williams and Wilkins. pg 2102 and 2103.

30. PFN - Proximal Femoral Nail

31. Rockwood CA. Rockwood and Green's Fractures in adults 7th edition. Philadelphia, PA: Lippincott Williams and Wilkins.pg 2085

32. The "Z-Effect" Phenomenon Defined: A Laboratory Study..Eric J. Strauss,1 Frederick J. Kummer,1 Kenneth J. Koval,2 Kenneth A. Egoll. Page 1.

33. F. Fogagnolo $\cdot$ M. Kfuri Jr $\cdot$ C. A. J. Paccola Intramedullary fixation of pertrochanteric hip fractures with the short AO-ASIF proximal femoral nail Arch Orthop Trauma Surg (2004) 124: 31-37 DOI 10.1007/s00402-003-0586-9

34. Proximal femoral nail - Standard and long PFN page 1 - 34

35. Muller M, Nazarian S, Koch P, Schatzker J. The comprehensive classification of fractures of long bones. Berlin: Springer-Verlag, 1990; doi:10.1007/978-3-64261261-9.

36. Mahoney FI, Barthel DW. Functional evaluation: the Barthel index. Md State Med J. 1965;14:615.

37. Kraus M, Krischak G, Wiedmann K, Riepl C, Gebhard F, Jo ckel JA, Scola A. Clinical evaluation of PFNAÒ and relationship between the tip-apex distance and mechanical failure. Unfall- chirurg. 2011;114:470-8. doi:10.1007/ s00113-011-1975-0.

38. Singh M, Nagrath AR, Maini PS. Changes in trabecular pattern of the upper end of the femur as an index of osteoporosis. J Bone Joint Surg Am. 1970;52:457-67.

39. Jongbloed L, Stacey S, Brighton C. Stroke rehabilitation: senso- rimotor integrative treatment versus functional treatment. Am J Occup Ther. 1989;43:391-7.

40. Verhofstad MH, van der Werken C. DHS osteosynthesis for stable pertrochanteric femur fractures with a two-hole side plate. Injury. 2004;35:999-1002.

41. Braithwaite RS, Col NF, Wong JB. Estimating hip fracture morbidity, mortality and costs. J Am Geriatr Soc. 2003;51: 364-70.

42. Ahrengart L, To "rnkvist H, Fornander $\mathrm{P}$, Thorngren KG, Pasanen L, Wahlstro "m P, Honkonen S, Lindgren U. A randomized study of the compression hip screw and Gamma nail in 426 fractures. Clin Orthop Relat Res. 2002;401:20922.

43. Utrilla AL, Reig JS, Mun ${ }^{\mathrm{OZ}}$ FM, Tufanisco CB. Trochanteric gamma nail and compression hip screw for trochanteric fractures: a randomized, prospective, comparative study in 210 elderly patients with a new design of the gamma nail. J Orthop Trauma. 2005;19:229-33.

44. Fogagnolo F, Kfuri M Jr, Paccola CA. Intramedullary fixation of pertrochanteric hip fractures with the short AO-ASIF proximal femoral nail. Arch Orthop Trauma Surg. 2004;124(1):31-7.

45. Pajarinen J, Lindahl J, Michelsson O, Savolainen V, Hirvensalo E. Pertrochanteric femoral fractures treated with a dynamic hip screw or a proximal femoral nail. A randomised study comparing postoperative rehabilitation. J Bone Joint Surg Br.2005;87(1):76-81.

46. Werner-Tutschku W, Lajtai G, Schmiedhuber G, Lang T, Pirkl C, Orthner E. Intra- and perioperative complications in the stabilization of per- and subtrochanteric femo- ral fractures by means of PFN. Unfallchirurg. 2002;105:881-5.

47. Kiran Kumar K.K. et al., Functional and radiological outcome of unstable intertrochanteric fractures Indian Journal of Orthopaedics Surgery 2017;3(3):304-307 